\title{
Pertumbuhan Bibit Bud Chips dari Nodus Berbeda pada Tanaman Kolesom (Talinum Triangulare (Jacq.) Willd.)
}

\section{(Bud Chips Seed Growth from Different Nodes in Kolesom Plants (Talinum Triangulare (Jacq.) Willd.)}

\author{
Putri Andini Mandasari $^{1^{*}}$ dan Sinar Suryawati ${ }^{1}$ \\ ${ }^{1}$ Program Studi Agroteknologi, Fakultas Pertanian Universitas Trunojoyo Madura \\ Jl. Raya Telang PO BOX 2, Kamal, Bangkalan, Indonesia \\ *Email korespondensi: andini1.utm@gmail.com
}

Diterima 26 Juni 2018/Disetujui 14 Agustus 2018

\begin{abstract}
Talinum triangulare is succulent plant used as a vegetable or traditional medicine. This give consequences of land expansions and improvement of the culture technique such as using good plant materials. This plant is propagated by seed or using cutting technique. The cutting technique using long stem consist multiple buds gives the consequence more stock plant are needed. Therefore using single buds (bud chips) can be used as an alternative way. This research was aimed to study the growth of bud chips Talinum triangulare using different nodes. Randomized Complete Block Design (RCBD) with three replication used in this reasearch. The treatment levels are $B C 1$ (first bud chips in the basal of stem), BC2, BC3, BC4, BC5, $B C 6, B C 7, B C 8$ and BC9. The result showed that the growth of Talinum triangulare was affected by the origin of bud chip. The first emergence of shoots from nodal segment no. eight $(B C 8)$ and nine $(B C 9)$ gave the fastest response compared to nodal segment no. one (BC1), two (BC2), and three (BC3) from the basal of stem. The leaf area, dry weight of leaf, root, stem, and dry weight total of biomass from nodal segment no. one (BC1) at the basal stem is the highest compared to other treatments.
\end{abstract}

Keywords: bud chips, seeds, Tanicum triangulare.

\section{ABSTRAK}

Kolesom merupakan tanaman yang berpotensi sebagai sayur dan obat. Pemanfaatan potensi kolesom membawa konsekuensi pada perluasan lahan penanaman dan perbaikan teknologi budidaya, diantaranya penggunaan bibit bermutu. Bibit kolesom dapat diperbanyak secara generatif dengan biji dan vegetative menggunakan stek. Penggunaan stek dengan beberapa ruas (banyak nodus) mengakibatkan kebutuhan stek semakin banyak. Oleh karena itu, stek satu mata tunas (bud chips) menjadi alternatif. Tujuan penelitian untuk mempelajari pertumbuhan bibit kolesom asal bud chips dari nodus berbeda. Taraf perlakuan mulai dari bud chip nodus nomor 1 dari pangkal batang (BC1), BC2, BC3, BC4, BC5, BC6, BC7, BC8 sampai BC9. Rancangan penelitian menggunakan Rancangan Acak Kelompok (RAK) dan masing-masing perlakuan diulang tiga kali. Hasil penelitian menunjukkan bahwa asal bud chips yang berbeda menghasilkan pertumbuhan yang berbeda pula; waktu pecah mata tunas perlakuan bud chip dari nodus nomor 8 dan 9 lebih cepat dibandingkan nodus nomor 1, 2 dan 3 dari pangkal batang; luas daun, berat kering organ daun, akar dan batang serta berat kering total/tanaman paling tinggi dicapai oleh perlakuan bud chip dari nodus nomor 1 dari pangkal batang.

Kata kunci: bud chips, bibit, kolesom.

\section{PENDAHULUAN}

Kebutuhan bahan baku tanaman obat terus meningkat seiring pola hidup masyarakat yang telah kembali menggunakan obat tradisional. Tanaman berkhasiat obat yang sedang banyak dibudidayakan antara lain kolesom (Tanicum triangulare). Kolesom juga dimanfaatkan untuk sayuran terutama daun dan pucuk (Rifai, 1994 dalam Mualim, 2012; Fasuyi, 2006 dalam Anna, 2010). Kecenderungan masyarakat kembali ke bahan alam dan kemanfaatan kolesom terhadap kesehatan membawa konsekuensi terhadap perluasan lahan dan perbaikan teknologi budidaya dengan penggunaan bibit yang bermutu.

Bibit kolesom dapat diperoleh dari perbanyakan generatif menggunakan biji dan perbanyakan dengan bagian vegetatif tanaman seperti stek, merunduk maupun bagian vegetatif lainnya namun yang banyak dilakukan terbatas pada penggunaan stek. Susanti (2008) menyebutkan bahwa bibit asal stek kolesom menghasilkan produksi biomassa tertinggi dibanding dengan biji. Penggunaan stek untuk bahan tanam menggunakan dasar ukuran panjang stek, belum tentu memiliki jumlah nodus yang sama karena dipengaruhi oleh banyak faktor seperti kondisi lingkungan. 
Lingkungan tumbuh yang ternaungi menyebabkan pertumbuhan tanaman cenderung etiolasi, sedangkan lingkungan yang tidak ternanungi dan terlalu panas menyebabkan pertumbuhan ruas-ruas tanaman memendek (roset). Jumlah ruas yang berbeda menyebabkan kompetisi dalam pertumbuhan tanaman. Kompetisi yang terjadi diantaranya persaingan antar bagian tanaman dalam aktivitas fotosintesis dan translokasi fotosintat. Apabila hal ini terjadi dalam tanaman maka sistem tajuk kurang baik akibat saling menutupi baik ranting maupun daun (nodus yang bagian atas menutupi nodus dibawahnya) sehingga biomassa yang dihasilkan kurang optimal. Selain hal tersebut, penggunaan stek dengan beberapa mata tunas atau nodus mengakibatkan bahan stek yang dibutuhkan lebih banyak. Stek satu mata tunas yang dikenal dengan istilah bud chips menjadi alternatif karena mengatasi akibat kurang baik pada stek yang lazim digunakan.

Bud chips merupakan mata tunas tunggal berasal dari mata tunas yang diambil dengan memotong sebagian ruas batang (Hunsigi, 2001). Situmeang et al. (2015) menyebutkan bahwa sumber bud chips berpengaruh nyata terhadap persentase tumbuh tunas, tinggi tanaman, dan diameter batang pada tanaman tebu. Lebih lanjut Hardjanti (2005 dalam Situmeang et al., 2015) menambahkan bahwa kemampuan stek membentuk akar dan tunas dipengaruhi kandungan karbohidrat dan keseimbangan hormon. Hal tersebut membuktikan bahwa kecepatan tumbuh atau kualitas bibit dipengaruhi oleh sumber bud chips. Dengan demikian permasalahan penggunaan bud chips terletak pada bud chips pada nodus mana yang paling baik dan dapat dijadikan sebagai bibit yang menjamin kecepatan tumbuh dan berkembang paling baik. Berdasarkan hal tersebut perlu dilakukan penelitian mengenai sumber bud chips menjadi sebuah bibit yang seragam khususnya pada tanaman kolesom. Tujuan penelitian ini untuk mempelajari pertumbuhan bibit kolesom yang berasal dari bud chips dengan nodus yang berbeda.

\section{METODE PENELITAN}

\section{Waktu dan Tempat}

Penelitian dilakukan mulai bulan Pebruari sampai Maret 2016 di Rumah Koleksi Biofarmaka Agroteknologi, Fakultas Pertanian Universitas Trunojoyo Madura.

\section{Alat dan Bahan}

Alat yang digunakan meliputi: pisau pemotong bud chips, pot tray, gunting, kaca pembesar, hand sprayer, cetok tanah, ayakan ukuran $\emptyset 2 \mathrm{~mm}$, timbangan analitik, dan oven. Bahan yang digunakan: tanaman kolesom (Tanicum triangulare) yang telah berbunga (Mualim et al., 2009), media tanam yang meliputi tanah mediteran dan kompos, air, aquades, plastik sampel, dan amplop sampel oven.

\section{Rancangan Penelitian}

Rancangan penelitian menggunakan Rancangan Acak Kelompok (RAK). Perlakuan yang diteliti adalah bud chips dari nomor nodus yang berbeda, yaitu : Bud chip nomor 1 dari pangkal batang (BC1), BC2, BC3, BC4, BC5, BC6, BC7, BC8 sampai nomer 9 (BC9). Perlakuan tersebut diulang sebanyak 3 (tiga) kali.

\section{Tahapan Penelitian}

Penelitian diawali dengan persiapan media tanam menggunakan tanah mediteran dan kompos dicampur berdasarkan bobot (2:1), penyiapan bud chips menggunakan batang kolesom dari tanaman yang telah berbunga dipotong ukuran $1 \mathrm{~cm}$, perlakuan mata tunas dengan Hot water Treatment (HWT), penanaman dengan membenamkan separuh bud chips dan posisi mata tunas berada disamping dekat permukaan tanah, pemeliharaan meliputi penyiraman dan penyiangan, dan pemanenan pada umur 1 (satu) bulan setelah tanam.

\section{Parameter Pengamatan}

Parameter yang diamati meliputi pecah mata tunas (hari setelah tanam), panjang batang ( $\mathrm{mm}$ ), jumlah daun (helai), luas daun (cm), jumlah akar, bobot kering akar $(\mathrm{mg})$, bobot kering batang $(\mathrm{mg})$, bobot kering daun $(\mathrm{mg})$ dan bobot kering total (mg).

\section{Analisis Data}

Data yang diperoleh dianalisis statistik dengan sidik ragam dan dilanjutkan dengan Uji Jarak Duncan (UJD) 5\% pada perlakuan yang berpengaruh nyata terhadap parameter pengamatan

\section{HASIL DAN PEMBAHASAN}

\section{Pecah Mata Tunas}

Pertumbuhan pada stek diawali dengan pecahnya mata tunas (Gambar 1). Berdasarkan Tabel 1. menunjukkan bahwa perlakuan bibit bud chips dari nodus berbeda berpengaruh nyata terhadap variabel pecah mata tunas. Perakuan bibit bud chip dari nodus dekat pangkal batang mengalami pecah mata tunas lebih lambat, sedangkan perlakuan bibit bud chip dari nodus yang jauh dari pangkal batang atau semakin keujung dari pangkal batang mengalami pecah mata tunas lebih cepat. Dengan demikian kecepatan umur pecah mata tunas dipengaruhi oleh pembentukan mata tunas pada batang. Umur mata tunas berkaitan dengan kedewasaan sel ataupun jaringan didalamnya. Mata tunas dekat pangkal batang umurnya lebih tua dan semakin jauh dari pangkal atau semakin keujung umurnya semakin muda. Anatomi batang dekat pangkal lebih keras dan berkayu sehingga sel dan jaringannya telah dewasa, dengan demikian keaktifan sel menginisiasi tunas dari mata tunas tidur menjadi lebih lambat dibandingkan 
dengan yang semakin keujung dari pangkal batang yang lebih lunak dan sel-selnya masih aktif membelah sehingga inisiasi tunas dari mata tunas tidur lebih cepat. Sejalan dengan Salisbury dan Ross (1995) yang menjelaskan bahwa, bagian ujung tajuk yang dalam hal ini dapat diartikan daerah semakin keujung dari pangkal batang mempunyai jaringan yang aktif membelah (meristem), pada daerah meristem ini terjadi pembelahan sel yang tak terbatas (aktif). Bila sel telah dewasa dan berhenti tumbuh, maka sel memperkuat dindingnya dengan mensekresi substansi pengeras kedalam dinding primernya. Sel lain menambahkan dinding sel sekunder diantara membran plasma dan dinding primer, dinding sekunder seringkali menumpuk membentuk menjadi lapisan lamina, memiliki matriks kuat dan tahan lama yang sanggup memberi perlindungan dan dukungan (berkayu) (Campbell et al., 2002).
Pertumbuhan batang berhubungan dengan pecah mata tunas, dengan kata lain semakin cepat mata tunas pecah maka batang akan cepat terbentuk. Secara umum, panjang batang terpanjang dicapai mata tunas yang semakin jauh dari pangkal batang karena umur pecah mata tunas lebih cepat dibandingkan dengan mata tunas yang semakin dekat dengan pangkal batang (Tabel 2).

Menurut Hardjanti (2005 dalam Situmeang, 2015), kemampuan stek membentuk akar dan tunas dipengaruhi kandungan karbohidrat dan keseimbangan hormon. Pada jaringan muda lebih banyak mensintesis hormon auksin. Enzim yang paling aktif diperlukan untuk mengubah triptofan menjadi IAA terdapat dijaringan muda, seperti meristem tajuk, serta daun dan buah yang sedang tumbuh (Salisbury dan Ross, 1995).

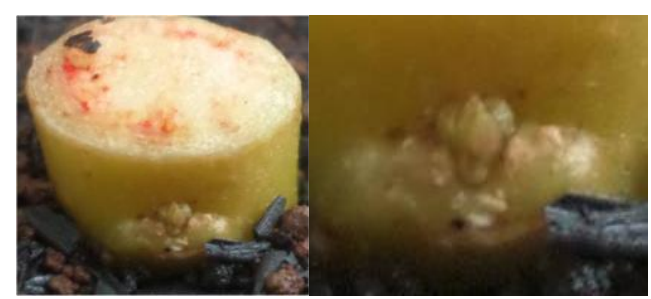

Gambar 1. Pecah mata tunas ditandai dengan membengkaknya daerah sekitar mata

Tabel 1. Rata-rata Pecah Mata Tunas (Hari Setelah Tanam) Bibit Bud chips dari Nodus Berbeda pada Tanaman Kolesom

\begin{tabular}{cl}
\hline Perlakuan & HST \\
\hline BC1 & $6,67 \mathrm{c}$ \\
BC2 & $6,33 \mathrm{c}$ \\
BC3 & $5,89 \mathrm{c}$ \\
BC4 & $5,22 \mathrm{bc}$ \\
BC5 & $5,22 \mathrm{~b}$ \\
BC6 & $4,11 \mathrm{ab}$ \\
BC7 & $4,00 \mathrm{ab}$ \\
BC8 & $3,89 \mathrm{a}$ \\
BC9 & $3,56 \mathrm{a}$ \\
\hline
\end{tabular}

Keterangan: Angka yang diikuti oleh huruf yang sama menunjukkan tidak berbeda nyata pada UJD 5\%

Tabel 2. Rata-rata Panjang Batang (mm) Bibit Bud chips dari Nodus Berbeda pada Tanaman Kolesom Pada Umur 10-30 HST

\begin{tabular}{|c|c|c|c|c|c|}
\hline Perlakuan & $10 \mathrm{HST}$ & $15 \mathrm{HST}$ & $20 \mathrm{HST}$ & $25 \mathrm{HST}$ & $30 \mathrm{HST}$ \\
\hline $\mathrm{BC} 1$ & $1,00 \mathrm{a}$ & $6,55 \mathrm{a}$ & 24,44 & $30,11 \mathrm{a}$ & $38,89 \mathrm{a}$ \\
\hline $\mathrm{BC} 2$ & $1,11 \mathrm{a}$ & $6,22 \mathrm{a}$ & 24,89 & $30,89 \mathrm{a}$ & 39,56 a \\
\hline BC3 & $1,33 \mathrm{ab}$ & $7,77 \mathrm{abc}$ & 23,44 & $31,33 \mathrm{a}$ & $38,89 \mathrm{a}$ \\
\hline BC4 & $1,78 \mathrm{abcd}$ & 7,88 abcd & 23,78 & $32,00 \mathrm{a}$ & $36,89 \mathrm{a}$ \\
\hline BC5 & $1,67 \mathrm{abc}$ & $6,88 \mathrm{ab}$ & 23,33 & $32,22 \mathrm{a}$ & $36,78 \mathrm{a}$ \\
\hline BC6 & 2,00 bcde & $9,33 \mathrm{abcd}$ & 23,78 & $32,44 \mathrm{a}$ & $39,33 \mathrm{a}$ \\
\hline BC7 & 2,11 cde & $10,80 \mathrm{bcd}$ & 24,22 & $34,00 \mathrm{a}$ & $40,00 \mathrm{a}$ \\
\hline BC8 & $2,67 \mathrm{e}$ & $11,44 \mathrm{~cd}$ & 25,33 & $36,22 \mathrm{ab}$ & $47,67 \mathrm{~b}$ \\
\hline BC9 & $2,33 \mathrm{de}$ & $12,11 \mathrm{~d}$ & 25,44 & $40,11 \mathrm{~b}$ & $51,00 \mathrm{~b}$ \\
\hline
\end{tabular}

Keterangan : Angka yang diikuti oleh huruf yang sama pada kolom yang sama menunjukkan tidak berbeda nyata pada UJD $5 \%$. 
Tabel 3. Rata-rata Jumlah Daun (helai) Bibit Bud chips dari Nodus Berbeda pada Tanaman Kolesom pada Umur 15-30 HST

\begin{tabular}{ccccc}
\hline Perlakuan & 15 HST & 20 HST & 25 HST & 30 HST \\
\hline BC1 & 1,78 & 5,44 & 7,44 & 7,67 \\
BC2 & 1,67 & 5,56 & 7,33 & 8,00 \\
BC3 & 2,78 & 6,11 & 7,00 & 7,89 \\
BC4 & 2,56 & 6,33 & 6,67 & 8,11 \\
BC5 & 2,78 & 6,22 & 6,78 & 7,67 \\
BC6 & 2,89 & 6,11 & 6,67 & 6,78 \\
BC7 & 3,11 & 5,89 & 6,44 & 7,00 \\
BC8 & 3,33 & 6,22 & 6,44 & 7,00 \\
BC9 & 3,22 & 6,33 & & \\
\hline
\end{tabular}

Tabel 4. Rata-rata Luas Daun (cm) Bibit Bud chips dari Nodus Berbeda pada Tanaman Kolesom pada Umur 30 HST

\begin{tabular}{cc}
\hline Perlakuan & $30 \mathrm{HST}$ \\
\hline BC1 & $23,49 \mathrm{c}$ \\
BC2 & $18,36 \mathrm{bc}$ \\
BC3 & $17,49 \mathrm{bc}$ \\
BC4 & $17,15 \mathrm{bc}$ \\
BC5 & $17,90 \mathrm{bc}$ \\
BC6 & $17,73 \mathrm{bc}$ \\
BC7 & $16,66 \mathrm{ab}$ \\
BC8 & $15,60 \mathrm{a}$ \\
BC9 & $10,16 \mathrm{a}$ \\
\hline
\end{tabular}

Keterangan : Angka yang diikuti oleh huruf yang sama menunjukkan tidak berbeda nyata pada UJD 5\%.

Tabel 6. Rata-rata Bobot Kering Akar, Batang, Daun dan Total (mg) Bibit Bud chips dari Nodus Berbeda pada Tanaman Kolesom pada Umur 30 HST

\begin{tabular}{cllll}
\hline Perlakuan & BK Akar $(\mathrm{mg})$ & BK Batang $(\mathrm{mg})$ & BK Daun $(\mathrm{mg})$ & BK Total $(\mathrm{mg})$ \\
\hline BC1 & $3,68 \mathrm{c}$ & $8,52 \mathrm{c}$ & $27,03 \mathrm{~d}$ & $39,23 \mathrm{c}$ \\
BC2 & $3,33 \mathrm{c}$ & $7,53 \mathrm{bc}$ & $25,73 \mathrm{~cd}$ & $36,60 \mathrm{bc}$ \\
BC3 & $2,30 \mathrm{~b}$ & $5,67 \mathrm{ab}$ & $21,82 \mathrm{bcd}$ & $29,79 \mathrm{abc}$ \\
BC4 & $2,09 \mathrm{ab}$ & $5,70 \mathrm{ab}$ & $21,36 \mathrm{abc}$ & $29,14 \mathrm{ab}$ \\
BC5 & $2,12 \mathrm{ab}$ & $5,89 \mathrm{ab}$ & $19,11 \mathrm{ab}$ & $27,12 \mathrm{a}$ \\
BC6 & $1,59 \mathrm{ab}$ & $3,91 \mathrm{a}$ & $17,03 \mathrm{ab}$ & $22,53 \mathrm{a}$ \\
BC7 & $1,39 \mathrm{a}$ & $3,70 \mathrm{a}$ & $13,83 \mathrm{a}$ & $18,92 \mathrm{a}$ \\
BC8 & $1,71 \mathrm{ab}$ & $5,26 \mathrm{a}$ & $15,80 \mathrm{ab}$ & $22,77 \mathrm{a}$ \\
BC9 & $1,22 \mathrm{a}$ & $3,69 \mathrm{a}$ & $15,00 \mathrm{a}$ & $19,91 \mathrm{a}$ \\
\hline
\end{tabular}

Keterangan : Angka yang diikuti oleh huruf yang sama pada kolom yang sama menunjukkan tidak berbeda nyata pada UJD $5 \%$.

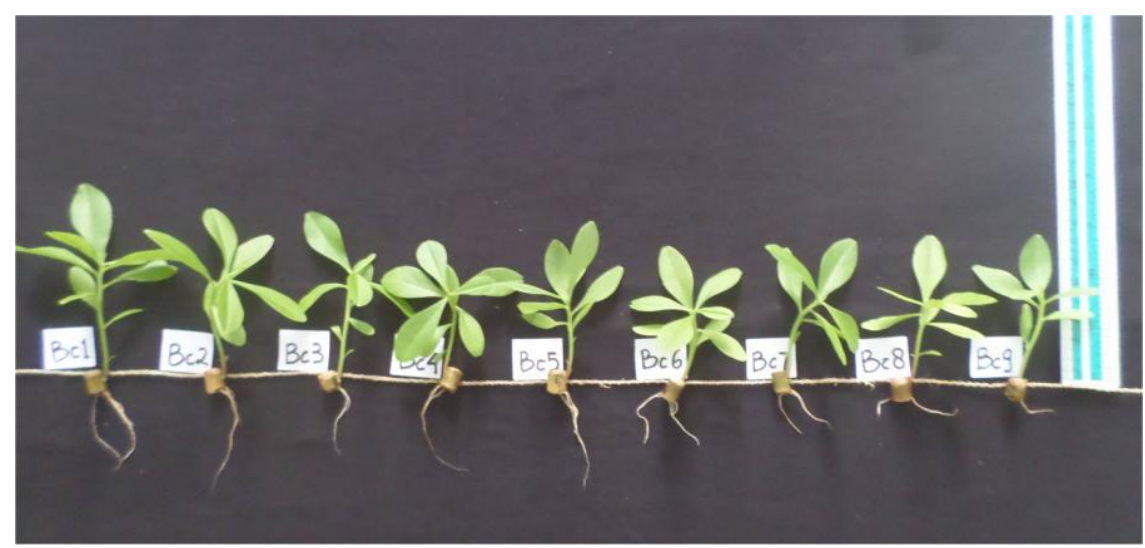

Gambar 2. Keragaan tanaman umur 30 hari setelah tanam (HST) 
Pertumbuhan batang diikuti oleh pembentukan daun pada batang-batang beruas, namun jumlah daun yang terbentuk tidak selalu mengikuti pertambahan ukuran panjang pada batang. Hal ini dapat diketahui pada sidik ragam variabel pertumbuhan panjang batang yang berpengaruh nyata, sedangkan jumlah daunnya tidak berpengaruh nyata pada setiap pengamatan yang dilakukan (Tabel 3). Pengamatan umur 5 dan 10 HST bibit bud chips masih ada yang belum membentuk daun, daun baru terbentuk secara keseluruhan pada umur 15 HST. Perlakuan bibit bud chips dari nodus berbeda sejak umur 15 hingga 30 HST menunjukkan tidak berpengaruh nyata terhadap variabel jumlah daun. Hal ini diduga karena faktor genetik tanaman kolesom. Pada umur 15 HST, jumlah daun terbanyak dibentuk pada bud chip di ujung sedangkan yang sedikit pada bud chip mendekati pangkal batang. Sejalan dengan pertambahan umur tunas jumlah daun yang terbentuk berangsur-angsur berubah. Perubahan terjadi antara umur 20 hingga $25 \mathrm{HST}$, dimana pada umur $20 \mathrm{HST}$ jumlah daun relatif sama antara bud chip dekat pangkal batang dengan bud chip yang terletak semakin keujung dari pangkal batang. Selanjutnya, pada umur 25 HST jumlah daun terbanyak pada bud chip dekat pangkal batang hingga umur $30 \mathrm{HST}$. Hal tersebut diduga karena kedewasaan sel dan jaringan pada bud chip dekat pangkal batang meningkat sehingga laju tumbuh untuk pembentukan daun kecenderungan lebih cepat dibandingkan dengan bud chip yang semakin keujung.

Hasil bobot kering batang paling berat dicapai oleh bud chip dekat pangkal batang, semakin keujung dari pangkal batang bobot keringnya semakin ringan (Tabel 6). Hal ini diduga karena pendewasaan sel antara lain pembesaran ukuran batang dan pembentukan jaringan pada batang bud chip dekat pangkal batang makin tebal sehingga menyebabkan bobot kering menjadi lebih berat dibandingkan dengan bud chip yang semakin keujung dari pangkal batang.

Luas daun pada umur 30 HST bibit bud chip dekat pangkal batang memperoleh luas daun terluas dan semakin ke ujung dari pangkal batang semakin sempit (Tabel 4). Hal ini diduga karena sel dan jaringan bud chip dekat pangkal batang lebih dewasa sehingga sel-sel pengangkut seperti pembuluh xilem dan floem serta jaringan lainnya lebih kuat dan lebar, hal tersebut memungkinkan proses transportasi air dan mineral dari akar melalui batang mata tunas dekat pangkal lebih lancar ke sel mesofil daun dan pada gilirannya fotosintesis lebih banyak terjadi karena bahan baku untuk fotosintesis lebih optimal. Daun akan meningkatkan luas permukaan untuk penguapan air yang keluar secara bebas dari stomata yang terbuka (Campbell et al., 2003).

Hasil bobot kering daun sejalan dengan luas daun yang terbentuk. Semakin luas suatu daun, bobot kering yang dihasilkan juga semakin berat. Perlakuan bibit bud chip dari nodus atau mata tunas dekat pangkal batang memperoleh bobot kering paling berat yaitu $27.03 \mathrm{mg}$ (Tabel 6).

Pertumbuhan tidak hanya meliputi hasil pertambahan nilai bobot kering diatas permukaan tanah, akan tetapi juga dinilai dari pertumbuhan didalam tanah antara lain jumlah dan bobot kering akar (Gambar 2.). Campbell et al., (2003) menjelaskan tentang sistem akar yaitu akar menyerap air dan mineral dan menghantarkan air dan nutrien, serta menyimpan cadangan makanan. Proses tersebut juga menjelaskan bahwa dalam pertumbuhan primer, akar terdorong menembus tanah dengan tudung yang mensekresikan lendir polisakarida untuk melumasi tanah disekitar ujung yang tumbuh.

Pertumbuhan akar pada bud chips terdiri atas beberapa akar primer yang terbentuk dari pangkal potongan batang yang kontak atau bersinggungan langsung dengan media. Dari akar primer tumbuh akar sekunder dan serta rambut-rambut akar. Perlakuan bibit bud chips dari nodus berbeda tidak berpengaruh nyata terhadap variabel jumlah akar. Hal tersebut diduga karena bud chip berasal dari satu batang tanaman kolesom secara utuh, sehingga diduga jumlah jaringan pembuluh yang terbentuk didalamnya jumlahnya sama namun berbeda pada pendewasaan dan ukuran vakuola.

Hasil sidik ragam bobot kering akar menunjukkan bahwa perlakuan bibit bud chips dari nodus berbeda berpengaruh nyata terhadap variabel bobot kering akar. Bobot kering akar paling berat dicapai perlakuan bibit bud chip dekat pangkal batang dan paling ringan diperoleh bud chip yang jauh dari pangkal batang (Tabel 6). Hal tersebut diduga karena kedewasaan sistem jaringan pada BC1. Campbell et al., (2003) maupun Salibusry dan Ross (1995) menjelaskan bahwa sebagian besar sel tumbuhan dewasa memiliki kompartemen / ruangan ketiga, yaitu vakuola yang dapat menempati $90 \%$ dari volume protoplas. Vakuola memiliki peran yang sangat penting dalam aktivitas pertumbuhan. Beberapa fungsi vakuola adalah tempat penyimpanan cadangan dan atau penimbunan ion dan senyawa organik, pembuangan limbah, perlindungan, dan pertumbuhan (Campbell et al., 2002). Bobot kering yang lebih berat pada bibit bud chip dekat pangkal batang terkait dengan peran pangkal batang sebagai penyimpanan cadangan. Hal tersebut terbukti dari variabel jumlah daun dan jumlah akar yang tidak berpengaruh nyata atau sama

Berdasarkan akumulasi bobot kering dari akar, batang dan daun terbentuklah bobot keseluruhan yaitu bobot kering total tanaman. Bobot kering total paling berat dicapai oleh bud chip yang dekat dengan pangkal batang. Hal ini akibat dari bobot kering pada akar, batang, dan daun pada bud chip dekat pangkal batang memperoleh bobot paling berat (Tabel 6). Berdasarkan hasil bobot kering total tanaman juga diketahui bahwa distribusi hasil fotosisntesis lebih banyak ke arah daun dibandingkan ke akar dan batang.

Distribusi hasil fotosintesis yang lebih banyak ke arah daun menjadikan bibit bud chip dekat pangkal batang lebih baik dibandingkan dengan bibit bud chip yang semakin ke unjung dari pangkal batang. Hal tersebut diketahui dari fungsi organ daun dalam pertumbuhan. Daun merupakan organ fotosintesis utama pada sebagian besar tumbuhan (Campbell et al., 2003).

\section{KESIMPULAN}

Berdasarkan hasil penelitian pertumbuhan bibit bud chips dari nodus berbeda pada tanaman kolesom dapat 
disimpulkan sebagai berikut:

1. Asal bud chips dari nodus berbeda menghasilkan pertumbuhan yang berbeda pula.

2. Waktu pecah mata tunas perlakuan bud chip dari nodus nomor 8 dan 9 lebih cepat dibandingkan nodus nomor 1 , 2 dan 3 dari pangkal batang.

3. Luas daun, berat kering organ daun, akar dan batang serta berat kering total/tanaman paling tinggi dicapai oleh perlakuan bud chip dari nodus nomor 1 dari pangkal batang.

\section{SARAN}

Berdasarkan hasil penelitian disarankan dilakukan penelitian lebih lanjut dilapang untuk mengetahui pertumbuhan tanaman kolesom menggunakan bibit bud chip nodus nomor 1 dari pangkal batang.

\section{DAFTAR PUSTAKA}

Anna, I.W. 2010. Produksi Pucuk Kolesom (Talinum triangulare (Jacq.) Willd.) pada Berbagai Interval Panen dan Frekuensi Pemupukan N dan K. Skripsi. Departemen Agronomi dan Hortikultura, Fakultas Pertanian, Institut Pertanian Bogor. Bogor.

Campbell, N.A., J.B. Reece., L.G. Mitchell. 2002. Biologi, Edisi Kelima Jilid 1. Jakarta (ID): Erlangga.
Campbell, N.A., J.B. Reece., L.G. Mitchell. 2003. Biologi Edisi Kelima Jilid 2. Erlangga. Jakarta

Husnigi, G. 2001. Sugarcane in Agriculture and Industry. Eastern Press. India.

Mualim, L. 2012. Produksi dan Kualitas Kolesom dengan Pemupukan Organik dan Inorganik. Disertasi. Sekolah Pascasarjana. Institut Pertanian Bogor. Bogor.

Situmeang, H.P., A. Barus, Irsal. 2015. Pengaruh Konsentrasi Zat Pengatur Tumbuh dan Sumber Bud chips Terhadap Pertumbuhan Bibit Tebu (Saccharum officinarum) di Pottray. 3(3) : 992-1004.

Susanti, H., S.A. Aziz, M. Melati. 2008. Produksi Biomassa dan Bahan Bioaktif Kolesom (Talinum triangulare (Jacq.) Willd) dari Berbagai Asal Bibit dan Dosis Pupuk Kandang Ayam. Buletin Agronomi. 36(1):4855

Mualim, L., S.A. Aziz, M. Melati. 2009. Kajian Pemupukan NPK dan Jarak Tanam pada Produksi Antosianin Daun Kolesom. Buletin Agronomi. 37(1):55-61.

Salisbury, F.B, C.W. Ross. 1995. Fisiologi Tumbuhan Jilid 1, Jilid 3. Terjemahan Institute Teknologi Bandung. Bandung. 